sights, although a little inconvenient for solving altitudes as in the Marcq Saint Hilaire method. The arithmetic is simple and interpolation is trivial, but the use of four-figure logarithms may lead to serious error when the tables are employed for reducing sights of bodies having small azimuths. This follows because error in longitude due to error in latitude varies as the cotangent of the azimuth and that error in longitude due to error in altitude varies as the cosecant of the azimuth.

Remarks made by Goodwin ${ }^{8}$ in respect of Martelli's Tables are interesting:

To this little work attaches the somewhat unique experience that, more or less violently assailed by the critics, it has contrived to survive the ordeal, has passed through edition after edition, and seems to have firmly established itself in the favour of practical seamen of various nationalities. . . .

Goodwin's remarks were written in 1914, but they could well have been written at least forty years later, at which time Martelli's Tables were still extensively used; and, no doubt, there are still navigators afloat who have used them to this very day.

\title{
REFERENCES
}

1 Lecky, S. T. L. (1894). Wrinkles in Practical Navigation, 9th edn. London.

2 Martelli, G. F. (1873). Tables of Logarithms. New Orleans.

3 Hopkins, H. V. (1937). Martelli's Tables, Nautical Mag, Vol. 138. Glasgow.

4 Anon. (1919). Short, Easy and Improved Method of finding the Apparent Time at Ship. Glasgow, London.

5 Brown, C. H., Written communication to Hopkins (op. cit.).

6 Willis, E. J. (1925). The Methods of Modern Navigation. New York.

7 Anon. (1955). Admiralty Manual of Navigation. Vol. III, London.

8 Goodwin, H. B. (19I4). Methods of mystery in nautical astronomy. Nautical Mag., Vol. 91 .

\section{'A Brief History of the Method of Fixing by Horizontal Angles'}

\section{from J. Dickson}

READERS of Captain Cotter's very interesting article 'A Brief History of the Method of Fixing by Horizontal Angles', may be interested to know that the possible use of the resection or three-point problem was appreciated by English mathematical practitioners of the seventeenth century.

Explanations have been given by John Collins, F.R.S. (1625-83), and Edmond Halley, F.R.S., Master and Commander, later Captain, Royal Navy and Astronomer Royal. It seems probable that Halley actually made some use of the principle when he charted the English Channel.

Dr. Angus Armitage and Dr. A. H. W. Robinson have explained Halley's method. 


\section{REFEREN CES}

Collins, J. (1674). A Chronographical Problem proposed by Mr. Richard Townely and solved by John Collins. Philosophical Transactions of the Royal Society, London.

Halley, E. (1702). Letter to Sir Robert Southwell reproduced in McPike, E. F. (1937), Correspondence and Papers of Edmond Halley, London.

Robinson, A. H. W. (1962). Marine Cartography in Britain, Leicester.

Armitage, A. (1966). Edmond Halley, London.

\section{from George A. Gibson}

C. H. Cotrer ${ }^{1}$ has detailed the history of many of the methods of obtaining a position on the chart corresponding to the horizontal angles, measured with a sextant, between one or more pairs of objects. The methods covered included the use of a station-pointer (tracing paper or instrument) when two of the angles between three objects are measured, and the geometrical construction of the arc of the circle which is the position line obtained from the angle between two objects. He did not mention the geometrical method in which the position line is approximated by a tangent to the circle.

The construction for this method is as shown in the diagram. A line $A E$ is drawn from one of the objects $A$, either through an estimated position $E$ or according to an approximate bearing of $A$. From the other object $B$ a line $B C$ is drawn at the measured angle to $A E$, meeting $A E$ at $C$. $C$ is then a point on the position line. $\mathrm{XY}$ is drawn through $\mathrm{C}$ such that $\angle \mathrm{ACX}=\angle \mathrm{ABC}$. $\mathrm{XY}$ is then the required line. As with all methods which involve approximating a circle by the tangent at a point, care is required if the true position is some distance from the point of tangency $\mathrm{C}$.

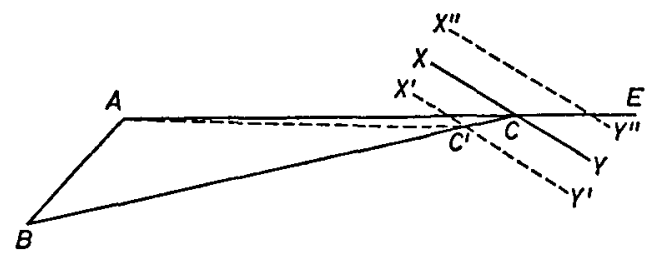

FIG. I

The method is particularly useful when the positions of the objects and the measured angle are such that the position circle is of large radius or has its centre off the chart. It therefore deals with the case when the measured angle is small, less than $30^{\circ}$, and it is difficult to construct the circle accurately by other methods. ${ }^{2}$ This situation commonly occurs when approaching a leading line.

An additional advantage is that little further construction is required to indicate the shift of the position line due to an error in the measurement of the angle. $\mathrm{X}^{\prime} \mathrm{Y}^{\prime}$ is drawn parallel to $\mathrm{XY}$ through $\mathrm{C}^{\prime}$ which is the point on $\mathrm{BC}$ such that $\angle C B C^{\prime}$ is the maximum expected error. $X^{\prime \prime} Y^{\prime \prime}$ is drawn on the opposite side of and equidistant from $X Y$. Then $X^{\prime} Y^{\prime}$ and $X^{\prime \prime} Y^{\prime \prime}$ are the expected limits for the position line. It is thus possible to plot the diamond of error on the chart, instead of using tabulated values of the maximum error of the fix, ${ }^{3}$ which, without considerable calculation, apply only to the case when equal maximum errors are envisaged in the horizontal angles measured between three objects. 


\section{REFERENCES}

1 Cotter, C. H. A Brief History of the Method of Fixing by Horizontal Angles. This Journal, $25,528$.

2 Reed's Nautical Almanac and Tide Tables for 1973, 250.

3 Admiralty Manual of Narigation, Vol. III, 172.

\section{from Charles H. Cotter}

Stemming from my short paper, ${ }^{1}$ I have received an interesting communication from Mr. M. M. Ittiso, a member of the Royal Institute serving with the Eastern Africa National Shipping Line, in which he describes an experience in which the method of fixing by horizontal angles proved valuable.

'. . . while steaming along the Japanese coast', writes Ittiso, 'a breakdown in electric power plunged the wheelhouse into darkness and rendered most of the navigational equipment useless ...'

By using the bridge wing gyro repeater as a dumb compass card, relative bearings of shore lights were observed and horizontal angles found from which the ship's position was fixed using Fry's method. The fixes obtained were used to determine the error of the magnetic compass (the sky being overcast at the time) and, after power had been restored, to check the gyro-compass error during the settling time.

Ittiso draws my attention to a method of fixing using horizontal angles in which it is not necessary to draw circles in the construction: the whole process being performed using a square protractor. The method is described with reference to the accompanying figure.

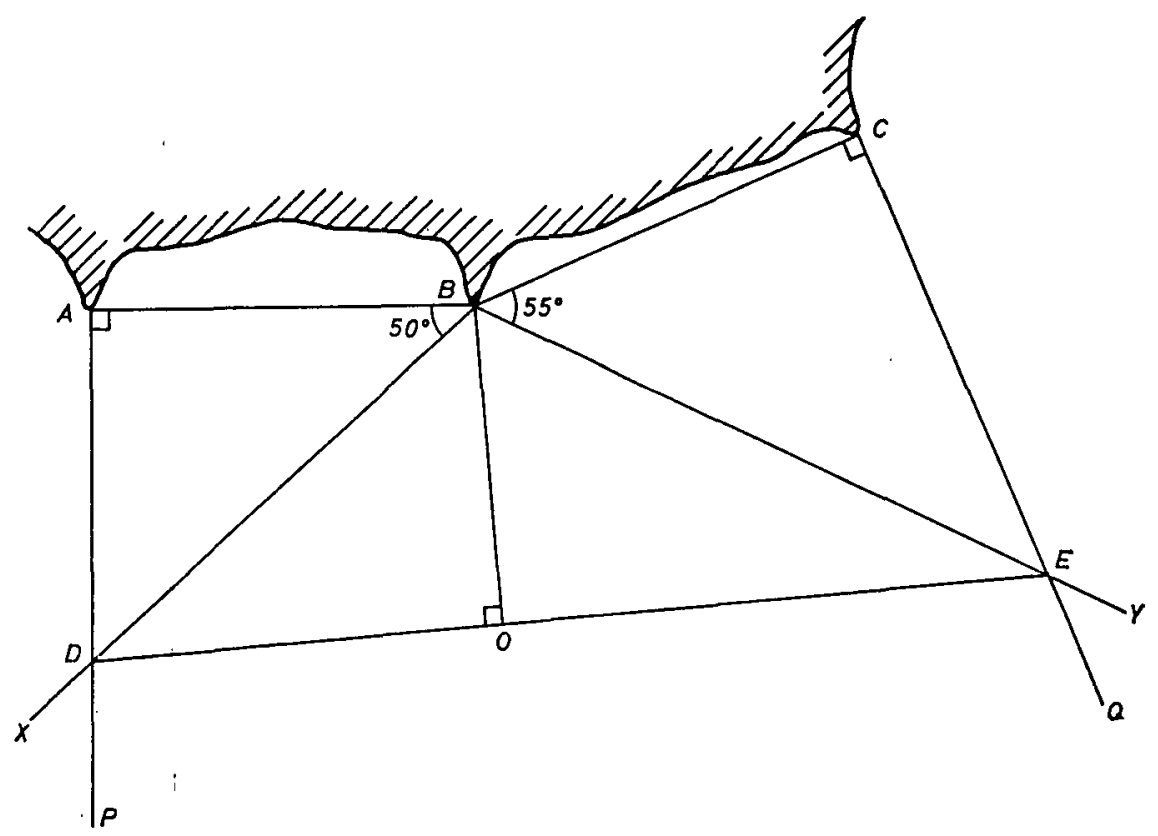

FIG. I 
In Fig. I suppose the horizontal angles between $A$ and $B$ and $B$ and $C$ to be $40^{\circ}$ and $35^{\circ}$ respectively. Join $A$ to $B$ and $B$ to $C$ as illustrated and construct angles $A B X$ and $C B Y$ equal respectively to the complements of the measured angles. Draw lines $A P$ and $C Q$ perpendicularly to $A B$ and $B C$ to cut $B X$ and $B Y$ respectively at $D$ and $E$. The ship's position is at $O$ such that $B O$ is perpendicular to the straight line joining $\mathrm{D}$ and $\mathrm{E}$. This is readily demonstrated using the facts that $\mathrm{BD}$ and $\mathrm{BE}$ are diameters of circles through $\mathrm{ABOD}$ and $\mathrm{CBOE}$ respectively, and the angles at $O$ standing on chords $A B$ and $B C$ are equal respectively to the measured angles $40^{\circ}$ and $35^{\circ}$. A fix is impossible if $D$ and $E$ are coincident so that, in general, the more widely spaced are $D$ and $E$ the more reliable is the fix.

In the example given both measured angles are less than $90^{\circ}$. In the event of a measured angle exceeding $90^{\circ}$ the construction is modified and it is not difficult to make the modification.

The method seems never to have been adopted by seamen, although the late Professor E. G. R. Taylor reminds us 10 that John Collins's Navigation by the Mariner's Plain Scale new plained; or a treatise of Geometrical and Arithmetical Navigation included 'one of Sutton's brass protractors in a cover pocket', so that there is the possibility that the method may be described in this book-and this I will endeavour to check in due course.

Transaction number $17^{11}$ of the Royal Society gives three chorographical problems solved by 'a Member of the Philosophical Society of Oxford'. The anonymous writer points out that the 'Problem may occur at Sea', and remarks that angles at a station may be measured by means of:

'... an Ordinary surveying semi-circle or Cross-Staff, or if the Objects be beyond the view of the naked Eye, with a Telescope Quadrant . . '

Problem 2 in Transaction 177 requires the fixing of two stations $A$ and E from horizontal angles measured at $A$ at which station objects $B$ and $C$ (but not $D$ ) and station $E$ are visible; and at $E$ at which objects $C$ and $D$ (but not $B$ ) and station $A$ are visible. The two graphical solutions given for this problem are based on Euclid (33.3), but are exceedingly cumbrous.

Commander Dickson also reminds us of Halley's letter to Sir Robert Southwell ${ }^{12}$, written in 1702 . In his letter Halley:

'... endeavoured to draw up such plain directions for making the survey of a Coast, as may be serviceable to any that have the will and opportunity to describe curiously any Shoals they are acquainted with . . .'

Halley's method for 'putting down the soundings in Sea-Charts in their proper places' is the commonly-used method of plotting two intersecting circles the centres having been found by constructing angles at the charted positions of the observed objects equal to the complements of the respective measured angles.

I am fairly confident that the interesting and simple method given by lttiso has never been described in any popular British navigational manual published during the last two centuries. On investigation I find that it is described by Albrecht and Vierow in the first edition, published in 1854 , of their textbook on navigation. 2 Their description indicates that the method was not novel at the time, and it is evident that the method originated before 1854 . It is described in every edition of Albrecht and Vierow, at least down to the seventh which was published in 1892 , but it seems to be absent from the more recent German texts including the Lehrbuch by Meldau and Steppes ${ }^{3}$ of 1931 . 
Fixing by horizontal angles receives no mention in the magnificent two-volume work by Gallo ${ }^{4}$ published in Trieste in 1851 , and the same applies to the Spanish work 5 by Terry y Rivas of 1897 . French authors describe the method: full accounts being given, for instance, by Dubois 6 in 1869 , and by Constan 7 in 1903 . The Italian professor Fortunato Imperata also describes it in his treatise 8 published in 1908.

It is curious that this method of fixing by horizontal angles, which is superior to the circle method, appears never to have crossed the English Channel or the North Sea to find its way into British navigation manuals, and it certainly would interest the writer to know who first described it.

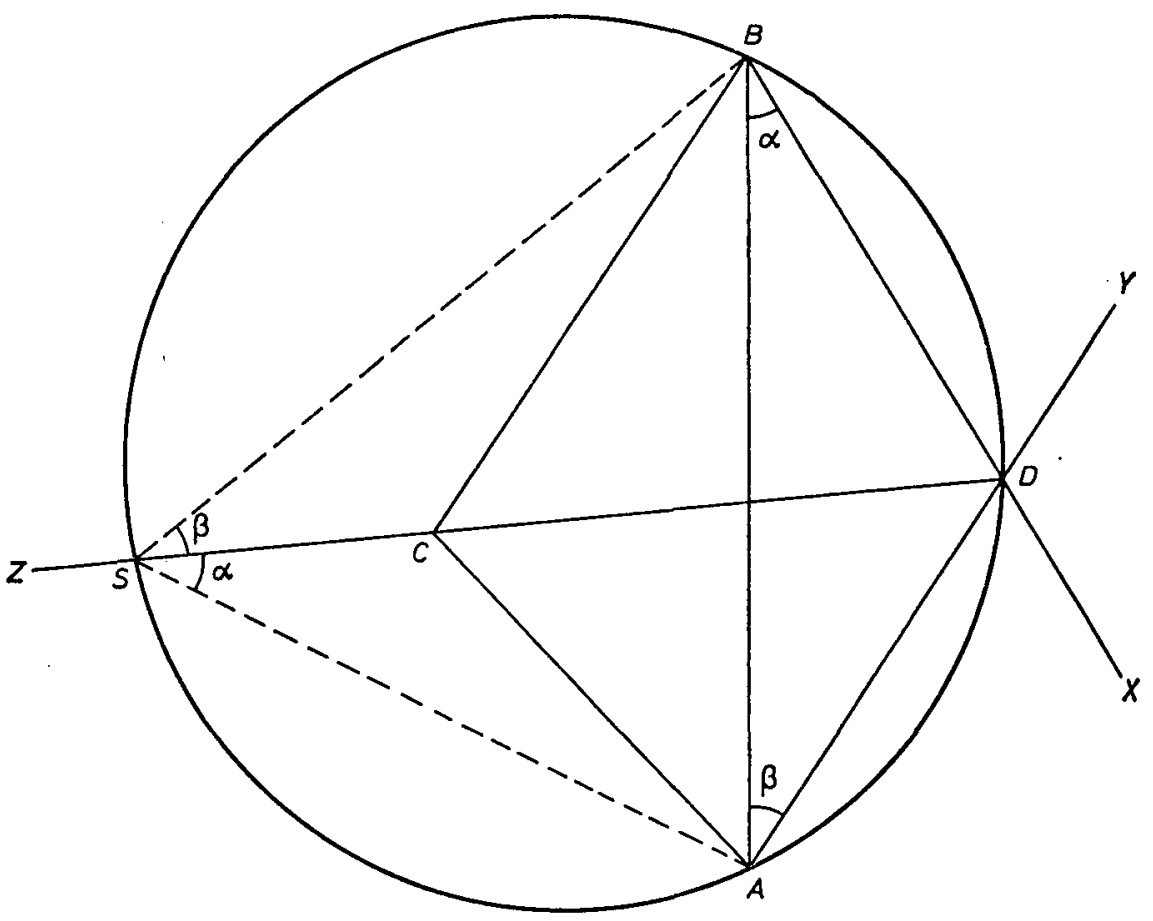

FIG. 2

The note from Commander J. Dickson draws attention to an early transaction 9 of the Royal Society. The problem in this early reference of 1674 -some half a century after Snell's use of the method-is :

'The Distances of three Objects in the same plane being given as A, B, C; the Angles made at a fourth Place in the same Plain as at $S$, are observed; the Distances from the Place of Observation to the respective Objects, are required.'

John Collins, F.R.S., in describing his solution of the Problem proposed by Richard Towneley, remarks:

'This Problem may be of good use for the due Situation of Sands or Rocks, that are within sight of three Places upon Land, whose distances are well 
known... especially now there is a Method of observing Angles nicely Accurate by Aid of the Telescope.' viz. :

Collins gives the solutions for each of six cases. His Case 4 is the most general,

'If the Station be without the Triangle made by the Objects, the sum of the Angles observed is less than four Right Angles.'

The method is described with reference to Fig. 2.

In Fig. 2, A, B and $C$ denote the three objects and $S$ the ship whose position is to be determined from measured angles ASC $(\alpha)$ and BSC $(\beta)$. Join A to B and lay off $B X$ and $A Y$ at angles $\alpha$ and $\beta$ at $B$ and $A$ respectively, to intersect at $D$. The straight line $\mathrm{DZ}$ through $\mathrm{D}$ and $\mathrm{C}$ passes through the ship's position, which is readily fixed by crossing the straight line $D Z$ with the circle through $A, D$ and B.

Sir Robert Southwell, diplomatist and friend of Samuel Pepys, doubtless informed the famous Secretary of the Navy of Halley's interest in navigation and hydrographic surveying, and it is by no means inappropriate to quote Pepys's opinion of Halley as summed up in one of his 'Naval Minutes':13

'Mr. Hawley (sic) - May he not be said to have the most, if not to be the first Englishman (and possibly any other) that had so much, or (it may be) any competent degree (meeting in them) of the science and practice (both) of navigation.'

\section{REFERENCES}

1 Cotter, C. H. (1972). A brief history of the method of fixing by horizontal angles. This Journal, 25, 528 .

2 Albrecht, M. F. and Vierow, C. F. (1854). Lehrbuch der Navigation und ihrer Mathematischen Hülfs-wissenschaften für die Konigl. Preussischen Navigations-schulen, Berlin; 2nd edition 1857 ; 3rd edition $1866 ; 4$ th edition 1873 ; 7 th edition 1892 .

3 Meldau, H. and Steppes, O. (1931). Lehrbuch der Navigation, Bremen.

4 Gallo, V. (1 851 ). Trattato di Navigatione. Trieste.

5 Terry y Rivas, A. (1897). Manual del Navegante. Madrid.

6 Dubois, E. (1869). Cours de Navigation et d'Hydrographie. Paris.

7 Constan, P. (1903). Cours Élémentaires d'Astronomie et de Navigation. Paris.

8 Imperato, F. (1908). Trattato Elementare di Navigazione Stimata. Milan.

9 Collins, J. (1674). A Chronographical Problem proposed by Mr. Richard Towneley and solved by John Collins. Phil. Trans. Royal. Soc. London.

10 Taylor, E. G. R. (1954). The Mathematical Practitioners of Tudor and Stuart England. Cambridge.

11 Anon. (1674). Three Chorographical Problems solved by a Member of the Philosophical Society at Oxford. Phil. Trans. Royal Soc. London.

12 Halley, E. (1 702). Letter to Sir Robert Southwell, Royal Society Collection of 'Newtoniana'. Reproduced in MacPike, E. E. (1932). Correspondence and Papers of Edmond Halley. Oxford.

13 Pepys, S. (c. 1696). Naval Minutes. Reproduced in Tanner, J. R. (1926). Samuel Pepys's Naval Minutes, Navy Records Society, Vol. LX, London. 